\title{
Correction to: On the pillars of Functional Analysis
}

\section{Victoria Velasco ${ }^{1}$}

Published online: 30 September 2021

(c) The Author(s) under exclusive licence to The Royal Academy of Sciences, Madrid 2021

\section{Correction to: RACSAM (2021) 115:173} https://doi.org/10.1007/s13398-021-01108-1

Unfortunately, the equation 2.5 is not updated correctly and the corrected equation is given below.

$$
\begin{gathered}
{ }^{0}\left(\left(B_{M+N}\right)^{0}\right) \subseteq\left(\left(B_{N}\left(0, \frac{1}{r}\right)+M\right)^{0}\right) \\
\overline{B_{M+N}}={ }^{0}\left(\left(B_{M+N}\right)^{0}\right) \text { and }{ }^{0}\left(\left(B_{N}\left(0, \frac{1}{r}\right)+M\right)^{0}\right)={ }^{\prime} \overline{B_{N}\left(0, \frac{1}{r}\right)+M}
\end{gathered}
$$

The Original Article was corrected.

Publisher's Note Springer Nature remains neutral with regard to jurisdictional claims in published maps and institutional affiliations.

The original article can be found online at https://doi.org/10.1007/s13398-021-01108-1.

M. Victoria Velasco vvelasco@ugr.es

1 Departamento de Análisis Matemático, Facultad de Ciencias, Universidad de Granada, 18071 Granada, Spain 